Original Article

\title{
Factors affecting the benefits of a six-month supervised exercise program on community-dwelling older adults: interactions among age, gender, and participation
}

\author{
Tuna Donat Hulya, PhD ${ }^{1)^{*}}$, Yeşilyaprak Subasi Sevgi Sevi, $\mathrm{PhD}^{2)}$, Acar Serap, PhD2), \\ OzCAN EDEER Ayse, $\mathrm{PhD}^{3)}$ \\ 1) Faculty of Health Sciences, Sifa University: Izmir, Turkey \\ 2) School of Physical Therapy and Rehabilitation, Dokuz Eylül University, Turkey \\ 3) Dominican College, USA
}

\begin{abstract}
Purpose] This study determined the effects of age, gender, and participation on the benefits of a 6-month supervised exercise program on older adults. [Subjects and Methods] Eighty-five (37 women, 48 men) community-dwelling older adults participated. The chair sit-and-reach test, the 8-foot up-and-go test, the 6-minute walk test, the Berg Balance Scale, lower-body flexibility, dynamic balance, aerobic endurance, balance, metabolic rate, muscle strength, and position sense were evaluated. Repeated-measures of analysis of variance was performed including dependent variables of age, gender, and participation in the exercise program as dependent inter-subject factors and time of assessment as an intra-subject factor. [Results] Mean exercise participation was $29.88 \pm 1.29$ sessions. Flexibility, balance, position sense, and strength showed a significant main effect of time. There was a significant gender interaction for right shoulder flexion strength and knee extension strength, a significant gender-participation interaction for pre-/post-intervention measures of functional mobility, and a significant age-participation interaction for flexibility. [Conclusion] Exercise training improved outcomes after 6 months of supervised exercise, but the changes were similar regardless of participation level. Changes in strength were more pronounced in men than women.

Key words: Exercise benefits, Older adults, Age
\end{abstract}

(This article was submitted Dec. 1, 2014, and was accepted Jan. 17, 2015)

\section{INTRODUCTION}

Promoting physical activity for older adults is especially important, because this population is the least physically active of any age group ${ }^{1,2)}$. Although no amount of physical activity can stop the biological aging process, regular exercise may minimize the physiological effects of a sedentary lifestyle and increase active life expectancy by limiting the development and progression of chronic diseases and disabling conditions ${ }^{3,4)}$. In the decade since the publication of the First Edition of the American College of Sports Medicine (ACSM) Position Stand entitled "Exercise and Physical Activity for Older Adults", a substantial body of evidence regarding the benefits of regular exercise and physical activity for older adults has been reported. In addition to new evidence regarding the importance of exercise and physical activity for healthy older adults, a growing

\footnotetext{
*Corresponding author. Tuna Hulya Donat (E-mail: hulya.
} donat@gmail.com)

(C2015 The Society of Physical Therapy Science. Published by IPEC Inc. This is an open-access article distributed under the terms of the Creative Commons Attribution Non-Commercial No Derivatives (by-ncnd) License $<$ http://creativecommons.org/licenses/by-nc-nd/3.0/>. body of knowledge supports the prescription of exercise and physical activity for older adults with chronic diseases and disabilities ${ }^{2,3)}$.

Motivation and compliance play significant roles in the success or failure of exercise programs for older adults ${ }^{5,6}$ ). Baker et al. conducted a meta-analysis of 15 related studies, eight of which included attendance continuity data; the mean attendance rate was $78.2 \%$ of sessions, ranging from a median of $62 \%$ in a community-based class program. Baker et al. also report that the frequency of exercise was most commonly 3 days per week (12 of 15 studies), with a frequency of twice per week in one study, and once per week in another 7 ). Boyette et al. state that "personal characteristics" are the most important determining factor when designing an exercise plan for older adults. They identified biomedical status, past exercise participation, and education in order of decreasing priority as the most important factors for the initiation phase ${ }^{8)}$. In addition, gender may also affect exercise participation ${ }^{2}$. Another meta-analysis by Trost et al. confirms the influence of several factors known to be correlates of sociodemographics that is social factors affecting physical activity, such as changes in marital status, obesity, smoking, lack of time, and past exercise behavior ${ }^{9}$.

In order to create an exercise program to which older adults will continuously adhere, health professionals must 
have a greater understanding of the determinants and factors that influence long-term exercise benefits and how healthcare practitioners can maximize those benefits for this age group. Although adults aged 65 years and older gain substantial health benefits from regular physical activity, few studies have identified factors affecting the degree to which older adults benefit from exercise. Therefore, this study determined the effects of age, participation, and gender on several parameters indicative of exercise benefits for older adults.

\section{SUBJECTS AND METHODS}

This study was as a single-blind, prospective, community-based clinical study. The participants were recruited from among older adults living in the region of Balçova municipality in Izmir, Turkey. The address records of adults aged 65 years and older were obtained from the local administrations of each district of the Balçova municipality with the permission of the governorship. All subjects were visited at their given addresses and given information about the study. Volunteers who met the inclusion criteria were assessed.

The inclusion criteria were as follows: between 65 and 90 years old, physically independent (i.e., able to walk $20 \mathrm{~m}$ without assistance or resting), no cognitive disorders or dementia, and at least 24 points (for educated participants) or 18 points (for uneducated participants) on the Mini Mental State assessment ${ }^{10)}$. Older adults who were blind or deaf, were recovering from an acute illness, or had any cardiac problems such as resting angina, recurrent heart failure, recurrent and uncontrolled arrhythmia, and recent uncontrolled hypertension were excluded.

A total of 3,939 older adults were visited at their homes and given information about this study. At these home visits, 673 older adults were recorded as volunteers. Among them, 261 visited the clinic for pre-exercise assessment. Owing to recent health status changes, 32 participants were excluded prior to assessment, resulting in 229 participants being assessed pre-exercise. From this group, 104 older adults participated in the 6-month supervised group exercise program, and 93 of them came to the post-exercise assessment after completing the program. Data from 85 participants were acceptable for analysis.

Informed consent was obtained immediately prior to data collection. The Ethical Committee of the Dokuz Eylül University approved the study protocol. The research study was complied with the principles of Decleration of Helsinki. After the participants were informed about the assessments and 6-month supervised group exercise program, demographic characteristics including age, gender, and chronic illness status were recorded. All assessments were conducted before and after the exercise program by the same physiotherapist.

Body mass index (BMI, $\mathrm{kg} / \mathrm{m}^{2}$ ) was calculated as a measure of body composition. The assessments used included the chair sit-and-reach test for lower-body flexibility, 8-foot up-and-go test for functional mobility, and the 6-minute walk test for aerobic endurance; all assessments were performed as described in "The senior fitness test" by Rikli and Jones ${ }^{11-13)}$; the intra-class reliability values for these test items were $0.89(0.79-0.93), 0.95$ (0.92-0.97), and 0.94

\section{(0.90-0.96), respectively ${ }^{14)}$.}

Balance was assessed by measuring how long the participants could perform right and left one-legged standing and tandem standing (up to 30 seconds, eyes open and closed). All tests were repeated three times, and the mean value (in seconds) was recorded for analysis ${ }^{15}$ 16). The reliability coefficients for one-legged standing for non-disabled and disables participants were 0.75 and 0.85 , respectively ${ }^{17)}$. The Berg Balance Scale (BBS) was also used as the gold standard assessment of balance. The BBS includes tasks such as standing with eyes closed, reaching, standing on one foot, and picking up objects from the floor. The maximum possible score on the BBS is 56, indicating excellent balance. The BBS has excellent test-retest reliability (intraclass correlation coefficient $=0.91$ ) and intra-rater reliability (intraclass correlation coefficient $=0.97$ ) among communitydwelling older adults ${ }^{18)}$ as well as excellent correlation with the Dynamic Gait Index $(r=0.67)^{19)}$.

Basal metabolic rate was determined by a body fat analyzer (Biodynamics B1A 310e Bioimpedance Analyzer, Shoreline, WA, USA) and recorded as kcal $/ \mathrm{day}^{-1}$. Bioimpedance analysis has been established as an appropriate method for estimating body composition in the elderly ${ }^{20,21)}$.

The strength of the right shoulder flexors and knee extensors was measured by computer-based manual muscle testing (Tracker II, JTech Medical, Salt Lake City, UT, USA). The right arm was positioned with $90^{\circ}$ shoulder flexion and the elbow in full extension to measure the strength of the shoulder flexors; for lower-extremity strength measurement, the knee was kept at $30^{\circ}$ flexion $^{22,23)}$. Reliable information can be obtained by raters using a portable manual muscle testing device if the examiners receive intensive training ${ }^{24)}$.

Position sense was assessed by using a goniometer for the right knee and an inclinometer (Dual Inclinometer Tracker II, JTech Medical, Salt Lake City, UT, USA) for the lumbar region, available as part of the Tracker system mentioned above. The inclinometer technique is highly reliable and valid for assessing lumbar flexion ${ }^{25)}$. A knee flexion angle of $60^{\circ}$ and $50 \%$ of participants' individual range of lumbar flexion motion were chosen as reference points for position sense assessment. The error between the angle that the participant reproduced and reference angles was recorded. The average of three measurements was used for analysis ${ }^{26-28)}$. The sequence of assessments was randomized for each participant, and 5-10 minutes rest was given between assessments.

The supervised exercise program (Table 1) was led by the same physiotherapist for 2 days per week over 6 months. The exercise program included strengthening exercises in sitting and standing positions as well as posture, balance, coordination, and functional activities. The same exercise program was applied to all participants, although there were some individual differences such as the resistance strength of the theraband or the size of the free weights used. Group exercise sessions were held in the gymnasium facility of Balçova municipality, and the municipality's service buses provided transportation for participants.

\section{Statistical analysis}

SPSS 16.0 Inc., Chicago, USA version was used for 
statistical analysis. Continuous dependent variables were evaluated for normality by using the Kolmogorov-Smirnov test with a Lilliefors significance correction. The arithmetic mean $(\overline{\mathrm{x}})$ and standard error (SE) were used for the data analysis. Other demographic characteristics are presented as numbers and percentages.

Repeated-measures ANOVA $(3 \times 2)$ was performed with gender, age, and exercise participation as dependent intersubject factors and independent time of measurement (pre-/ post-exercise) as the intra-subject factor. The mean values of age and exercise participation were calculated in order to categorize these variables for inclusion in the analysis. Participants were categorized as "young-old" (65-69 years old) or "old-old" ( $\geq 70$ years) and "higher participated" $(\geq 29.88$ sessions) or "lower participated" ( $<29.88$ sessions) according to the mean number of sessions that the overall study sample participated in $(29.88 \pm 1.29$ sessions $)$. Significant main effects and interactions were determined at an $\alpha$ level of 0.05 for all ach analyses.

\section{RESULTS}

Data from 85 participants (37 women and 48 men) were used for analysis. Their mean age was $69 \pm 0.44$ years (range: 65-84 years). The participants' characteristics are summarized in Table 2. The participants participated in a mean of $29.88 \pm 1.29$ exercise sessions (57\%; range: $5-52$ sessions) in 6 months. Table 3 shows the outcomes before and immediately after the 6-month supervised group exercise program.

Measures of flexibility, balance, functional mobility, position sense, and strength pre- and post-intervention showed a

Table 1. Supervised exercise program

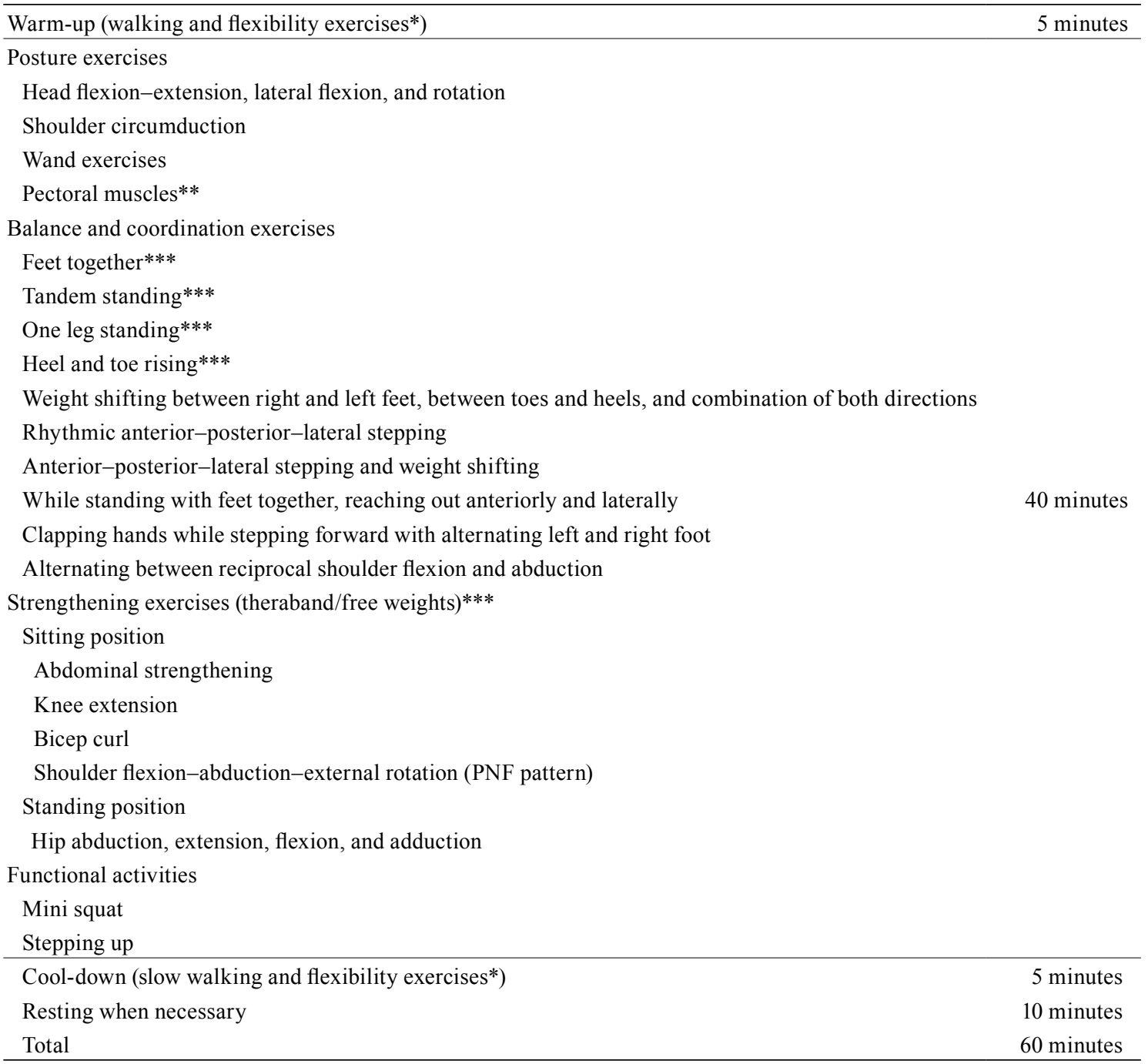

*Shoulder and trunk flexibility, gastrocnemius and quadriceps stretching, and hip adductor and hamstring stretching in the sitting position.

**Beginning with arms in the reverse $\mathrm{T}$ position, the arms are closed; the arms are then moved together by putting the forearms together in front of the head until they touch and then opened again.

$* * *$ Progression: eyes open to eyes closed, fixed head-to-head rotation.

****Progression: 6 repetitions of 2 sets to 10 repetitions of 3 sets with 10 seconds of rest between each repetition and 1 minute of rest between sets. 
significant main effect for time $(\mathrm{p}<0.05)$ (Table 3$)$, whereas the pre-/post-intervention comparison of 6-minute walking distance, BMI, and metabolic rate did not show significant main effects $(\mathrm{p}>0.05)$.

There were significant associations between gender and right shoulder flexion strength $(F=17.02, \mathrm{p}=0.000)$ and knee extension strength $(F=12.66, \mathrm{p}=0.001)$. Shoulder flexion strength and knee extension strength were greater in males than females.

The main effect of age interaction was not significant for any measurement $(p>0.05)$. There was no effect of age (i.e., young-old vs. old-old) on exercise benefits.

The main effect of participation interaction was nonsignificant for all parameters $(\mathrm{p}>0.05)$. Participation level was not associated with a change in exercise benefits.

There was no significant interaction between age and gender for flexibility, balance, functional mobility, position sense, or measures of strength $(p>0.05)$. There was a

Table 2. Participants' demographic characteristics

\begin{tabular}{lccc}
\hline & & $\mathrm{n}$ & $\%$ \\
\hline Age (years) & & & \\
Gender $\quad$ Female (n) & 37 & 43.5 \\
& Male (n) & 48 & 56.5 \\
Chronic health problems (n) & 0 & 12 & 14.1 \\
(musculoskeletal, cardiovascular, respiratory, & 1 & 15 & 17.6 \\
diabetes mellitus, digestive system, renal- & 2 & 20 & 23.5 \\
bladder and urinary system, neurological, & 3 & 21 & 24.7 \\
mental or emotional, hematologic, ocular) & $\geq 4$ & 17 & 20.0 \\
\hline
\end{tabular}

significant interaction between gender and participation for pre-/post-intervention measures of functional mobility $(F=$ $4.10, \mathrm{p}=0.046)$. Higher participated males showed greater improvement in functional mobility than higher participated females. Meanwhile, lower participated females showed more improvement than higher participated females.

There was a significant interaction between age and participation for flexibility $(F=4.37, \mathrm{p}=0.040)$. Higherparticipated old-old in comparison to lower-participated young-old group showed greater improvements in flexibility.

The interactions among participation, age, and gender were non-significant for flexibility, balance, functional mobility, or measures of position sense or strength $(p>0.05)$. The 6-minute walking test, BMI, and metabolic rate did not show a significant main effect of time, exercise participation, age, gender, or any of the other interactions $(p>0.05)$ (Table 4).

\section{DISCUSSION}

Community-based physical activity programs are effective for significantly improving performance measures including strength, flexibility, and balance among others $^{4,7,29-31)}$. However, adherence to regular exercise remains a problem among the elderly population ${ }^{2}$. The influences of general factors and personal characteristics on exercise behavior and participation have been studied mostly in the elderly population ${ }^{5,8,32-34)}$. However, the most appropriate exercise program structure (i.e., number of sessions, duration, etc.) and factors that may affect the benefits of exercise in older adults have not been established. Therefore, this study aimed to determine the effects of age, gender, and par-

Table 3. Parameters before and after exercise

\begin{tabular}{|c|c|c|c|c|c|c|}
\hline & & & \multicolumn{2}{|c|}{ Pre-exercise } & \multicolumn{2}{|c|}{ Post-exercise } \\
\hline & & & $\overline{\mathrm{x}} \pm \mathrm{SE}$ & Range & $\overline{\mathrm{x}} \pm \mathrm{SE}$ & Range \\
\hline BMI $\left(\mathrm{kg} / \mathrm{m}^{2}\right)$ & & & $28.84 \pm 0.46$ & $19.8-40.10$ & $28.59 \pm 0.48$ & $20.00-43.90$ \\
\hline Lower-body flexibility $(\mathrm{cm})$ & & & $-1.01 \pm 1.41$ & $-39-33$ & $2.26 \pm 1.27^{*}$ & $-33-30$ \\
\hline Functional mobility (s) & & & $7.27 \pm 0.17$ & $4.50-12.90$ & $6.91 \pm 0.13^{*}$ & $4.28-11.40$ \\
\hline Six-minute walk test (m) & & & $457.16 \pm 103.49$ & $135-742$ & $475.29 \pm 85.65$ & $247-664$ \\
\hline Balance & & & $28.84 \pm 0.46$ & $19.8-40.10$ & $28.59 \pm 0.48$ & $20.00-43.90$ \\
\hline \multirow[t]{3}{*}{ Eyes open (s) } & One leg standing & Right & $21.67 \pm 1.04$ & $0-30$ & $26.64 \pm 0.82 *$ & $0-30$ \\
\hline & & Left & $21.47 \pm 1.10$ & $0-30$ & $25.76 \pm 0.88^{*}$ & $2.7-30$ \\
\hline & Tandem & & $27.55 \pm 0.75$ & $2-30$ & $29.37 \pm 0.41 *$ & $1-30$ \\
\hline \multirow[t]{3}{*}{ Eyes closed (s) } & One leg standing & Right & $6.46 \pm 0.70$ & $0-30$ & $9.33 \pm 0.78^{*}$ & $0-30$ \\
\hline & & Left & $4.98 \pm 0.50$ & $0-30$ & $9.15 \pm 0.80$ & $0-30$ \\
\hline & Tandem & & $18.68 \pm 1.20$ & $0-30$ & $24.67 \pm 0.98$ & $1-30$ \\
\hline Berg Balance Scale (score) & & & $55.11 \pm 0.19$ & $46-56$ & $55.79 \pm 0.09 *$ & $51-56$ \\
\hline \multicolumn{7}{|l|}{ Position sense (degree) } \\
\hline Right knee & & & $4.68 \pm 0.48$ & $0.00-30.60$ & $2.71 \pm 0.21^{*}$ & $0.00-12.60$ \\
\hline Lower back & & & $3.64 \pm 0.30$ & $0.00-16.60$ & $2.73 \pm 0.23^{*}$ & $0.00-8.66$ \\
\hline Metabolic rate (kcal/day) & & & $1,545.45 \pm 29.57$ & $999-2403$ & $1,527.32 \pm 31.04$ & $938-2,345$ \\
\hline \multicolumn{7}{|l|}{ Strength (kg, right) } \\
\hline Shoulder flexion & & & $13.66 \pm 0.47$ & $5-23$ & $19.34 \pm 0.79 *$ & $7-47$ \\
\hline Knee extension & & & $17.54 \pm 0.65$ & $7-32$ & $25.21 \pm 0.95^{*}$ & $7-59$ \\
\hline
\end{tabular}

$* \mathrm{p}<0.05$ vs. pre-exercise 
ticipation on the benefits of a 6-month supervised exercise program for older adults.

Eighty-five community-dwelling older adults were evaluated before and after the 6-month supervised exercise program. The participants participated in $57 \%$ of the sessions (mean: $29.88 \pm 1.29$ sessions, range: $5-52$ sessions). After 6 months of exercise, there were significant improvements in flexibility, balance, functional mobility, position sense, and strength. However, there were no improvements in the 6-minute walking distance, BMI, or metabolic rate. It is well known that BMI, metabolic rate, and aerobic capacity can be affected by nutrition and aerobic activity; however, our intervention included neither. In addition, in their meta-analysis, Baker et al. concluded that multi-modal exercise programs, even those including aerobic exercise, may not result in a significant increase in 6-minute walking distance ${ }^{7}$. These two facts may explain the lack of statistically significant improvements in BMI, metabolic rate, and 6-minute walking distance in the present study.

In this study, males showed significantly more improvement in strength than females. Similarly, in a study by Beneka et al., males demonstrated greater improvement of knee extension power than females ${ }^{35)}$. This demonstrates that there is a gender-strength interaction and that strength improvement in older males is greater than that in older females after exercise intervention. In addition, the greatest improvement in functional mobility was observed in males with higher exercise participation, whereas males who participated less showed no change or a slight decrease. The greatest improvement in flexibility was observed in young-old adults - even in those who participated less - and old-old adults with higher participation in the exercise program. This may be attributable to a lower baseline level of flexibility in the young-old who participated less and the oldold who participated more than that in the young-old who participated more and the old-old who participated less. It is likely that the participants' initial level of flexibility also had an important effect on the benefits of exercise. In addition, it can be speculated that the old-old elderly may improve their flexibility with greater participation in the exercise program, whereas the young-old elderly benefit from the exercise program regardless of participation.

The main effect of age alone was non-significant for all parameters in the present study; the young-old and old-old elderly showed similar improvements. Similarly, in a community-based elderly study by Toraman and Sahin, exercise induced significant increases in all functional fitness tests (i.e., chair sit-and-reach, arm curls, chair stand, and 6-minute walk test scores) in both the younger and older elderly groups; the rate of restoration of function was approximately equivalent in both groups as well ${ }^{36)}$.

Littbrand et al. report that older age and female gender do not seem to negatively affect functional balance from a highintensity functional weight-bearing exercise program ${ }^{37)}$. They conclude that regardless of gender or age, older adults can benefit from exercise intervention and they need encouragement to attend any activity. Similarly, our results show that the age-gender interaction did not affect balance, functional mobility, or position sense. Hence, regardless of age or gender, elderly people may benefit from participating in an exercise program.

The main effect of participation alone was non-significant on the parameters that improved significantly; older adults showed similar improvements in all parameters regardless of participation. Concordantly, Nakagava et al. report that a simple exercise program for older adults under the instruction of a physiotherapist provides improvements in the functional reach test and balance tests regardless of participation ${ }^{38)}$. Participating in a regular exercise program improves older adults' health profile, even with lower participation rates. In other words, any kind of activity or exercise participation can result in some improvements in older adults; therefore, encouraging elderly people to perform any activity or exercise is vital, because interventions, especially those aiming to promote participation, also improve social integration and quality of life as reported by Kim et al ${ }^{39}$.

One of the strengths of this study is that all participants lived in the same region of a municipality in Izmir, Turkey and therefore had similar socioeconomic status. Although pre- and post-exercise assessments were performed in differ-

Table 4. Age, gender, and participation interaction for pre- and post-exercise measurements

\begin{tabular}{lllcc}
\hline Variable & & & $\begin{array}{c}\text { Pre-exercise } \\
(\overline{\mathrm{x}} \pm \mathrm{SE})\end{array}$ & $\begin{array}{c}\text { Post-exercise } \\
(\overline{\mathrm{x}} \pm \mathrm{SE})\end{array}$ \\
\hline Gender interaction for right & Right shoulder flexion & Male & $14.98 \pm 0.62$ & $23.04 \pm 0.95^{*}$ \\
shoulder flexion strength & strength $(\mathrm{kg})$ & Female & $11.95 \pm 0.64$ & $14.54 \pm 0.81$ \\
\hline Gender interaction for right & Right knee extension & Male & $19.13 \pm 0.92$ & $29.31 \pm 1.20^{*}$ \\
knee extension strength & strength (kg) & Female & $15.49 \pm 0.79$ & $19.89 \pm 0.98$ \\
\hline Gender versus participa- & Functional mobility & Higher-participated males & $7.08 \pm 0.33$ & $6.38 \pm 0.22^{*}$ \\
tion interaction for pre-/ & (8-foot up-and-go test) $(\mathrm{s})$ & Higher-participated females & $7.88 \pm 0.39$ & $7.70 \pm 0.35$ \\
post-exercise measures of & & Lower-participated males & $6.60 \pm 0.23$ & $6.69 \pm 0.25$ \\
functional mobility & & Lower-participated females & $7.61 \pm 0.27$ & $7.28 \pm 0.18^{*}$ \\
\hline Age versus participation & Flexibility $(\mathrm{cm})$ & Higher-participated old-old elderly & $-7.3 \pm 2.09$ & $-2.8 \pm 2.55^{*}$ \\
interaction for flexibility & & Higher-participated young-old elderly & $2.19 \pm 2.52$ & $3.59 \pm 2.14$ \\
& & Lower-participated old-old elderly & $1.86 \pm 3.9$ & $3.93 \pm 3.8$ \\
& & Lower-participated young-old elderly & $-1.04 \pm 2.76$ & $4 \pm 2.15^{*}$ \\
\hline
\end{tabular}

${ }^{*} \mathrm{p}<0.05$ vs. pre-exercise 
ent seasons because of the duration of the exercise program, they were performed in the same closed environmental conditions. Furthermore, with a duration of 6 months, the community-based supervised exercise program used in this study is one of the longest reported in the literature.

Although the region selected for this study has a large population of older adults, the number of older adults analyzed was much less than expected because of the drop outs and missing data. Willingness to participate in the study was limited even though the municipality provided transportation to participants as needed. Therefore, the results of this study are limited by the small sample size.

In conclusion, the 6-month exercise program resulted in improvements in all parameters. The results have some critical implications for health professionals. First, old-old elderly should be encouraged to participate in exercise programs in order to improve flexibility. Muscle strength improves after suitable exercise in both genders, although the improvement is greater in males than females. Although older males showed improvements in functional mobility, their functional mobility was worse than that in older females; therefore, males should participate more in exercise programs to improve their functional mobility. Hence, a 6-month supervised exercise program involving posture, strengthening, balance, and coordination exercises and functional activities can improve strength, flexibility, balance, functional mobility, and position sense in communityliving older adults regardless of gender, age, or participation; however, they may not see improvements in BMI, aerobic capacity, or metabolic rate.

Future studies should include an aerobic exercise program. The same design as that used herein could be applied to a larger sample performing an unsupervised home exercise program. Measurements could be repeated at the beginning, mid-point, and end of the exercise program in order to determine the long-term effects of age, gender, and participation on the benefits of a 6-month supervised exercise program in older adults.

\section{ACKNOWLEDGEMENT}

The authors sincerely thank the Mayor of Balçova for supporting this study.

\section{REFERENCES}

1) Mazzeo RS, Cavanagh P, Evans WJ, et al.: American College of Sports Medicine Position Stand. Exercise and physical activity for older adults. Med Sci Sports Exerc, 1998, 30: 992-1008. [Medline] [CrossRef]

2) Schutzer KA, Graves BS: Barriers and motivations to exercise in older adults. Prev Med, 2004, 39: 1056-1061. [Medline] [CrossRef]

3) Tiedemann A, Sherrington C, Lord SR: Predictors of exercise adherence in older people living in retirement villages. Prev Med, 2011, 52: 480-481. [Medline] [CrossRef]

4) Yeom HA, Keller C, Fleury J: Interventions for promoting mobility in community-dwelling older adults. J Am Acad Nurse Pract, 2009, 21: 95 100. [Medline] [CrossRef]

5) van der Bij AK, Laurant MG, Wensing M: Effectiveness of physical activity interventions for older adults: a review. Am J Prev Med, 2002, 22: 120-133. [Medline] [CrossRef]

6) Van Norman K: Motivation and compliance in exercise programs for older adults. J Phys Educ, Recreat Dance, 1998, 69: 24-27. [CrossRef]

7) Baker MK, Atlantis E, Fiatarone Singh MA: Multi-modal exercise pro- grams for older adults. Age Ageing, 2007, 36: 375-381. [Medline] [CrossRef]

8) Boyette LW, Lloyd A, Boyette JE, et al.: Personal characteristics that influence exercise behavior of older adults. J Rehabil Res Dev, 2002, 39: 95-103. [Medline]

9) Trost SG, Owen N, Bauman AE, et al.: Correlates of adults' participation in physical activity: review and update. Med Sci Sports Exerc, 2002, 34: 1996-2001. [Medline] [CrossRef]

10) McDowell I, Newell C: Mental status testing. In: Measuring health-A guide to rating scales and questionnaire, 2nd ed. New York: Oxford University Press, 1996, pp 314-322.

11) Jones J, Rikli RE: Measuring functional fitness of older adults. J Active Aging, 1997 (March-April): 24-30.

12) Mobily KE, Mobily PR: Reliability of the $60+$ functional fitness test battery for older adults. J Aging Phys Act, 1997, 5: 150-162.

13) Morrow JR, Jackson AW, Disch JG, et al.: Physical fitness and activity assessment in adults. "older adult fitness battery". In: Measurement and evaluation in human performance, 3rd ed. USA: Human Kinetics, 2005, pp $258-267$.

14) Rikli RE, Jones CJ: Development and validation of a functional fitness test for community-residing older adults. J Aging Phys Act, 1999, 7: 129-161.

15) Becker C, Kron M, Lindemann U, et al.: Effectiveness of a multifaceted intervention on falls in nursing home residents. J Am Geriatr Soc, 2003, 51: 306-313. [Medline] [CrossRef]

16) Hiroyuki S, Uchiyama Y, Kakurai S: Specific effects of balance and gait exercises on physical function among the frail elderly. Clin Rehabil, 2003, 17: 472-479. [Medline] [CrossRef]

17) Giorgetti MM, Harris BA, Jette A: Reliability of clinical balance outcome measures in the elderly. Physiother Res Int, 1998, 3: 274-283. [Medline] [CrossRef]

18) Berg KO, Wood-Dauphinee SL, Williams JI, et al.: Measuring balance in the elderly: validation of an instrument. Can J Public Health, 1992, 83: S7-S11. [Medline]

19) Shumway-Cook A, Baldwin M, Polissar NL, et al.: Predicting the probability for falls in community-dwelling older adults. Phys Ther, 1997, 77: 812-819. [Medline]

20) Berger VA, Rousset P, MacCormack C, et al.: Reproducibility of body composition and body water spaces measurements in healthy elderly individuals. J Nutr Health Aging, 2000, 4: 243-245. [Medline]

21) Hughes VA, Evans WJ: Assessment of fat-free mass in an older population using bioelectrical impedance. Fed Proc, 1987, 46.

22) Katula JA, Sipe M, Rejeski WJ, et al.: Strength training in older adults: an empowering intervention. Med Sci Sports Exerc, 2006, 38: 106-111. [Medline] [CrossRef]

23) Roy JS, MacDermid JC, Orton B, et al.: The concurrent validity of a hand-held versus a stationary dynamometer in testing isometric shoulder strength. J Hand Ther, 2009, 22: 320-326, quiz 327. [Medline] [CrossRef]

24) Ottenbacher KJ, Branch LG, Ray L, et al.: The reliability of upper- and lower-extremity strength testing in a community survey of older adults. Arch Phys Med Rehabil, 2002, 83: 1423-1427. [Medline] [CrossRef]

25) Saur PM, Ensink FB, Frese K, et al.: Lumbar range of motion: reliability and validity of the inclinometer technique in the clinical measurement of trunk flexibility. Spine, 1996, 21: 1332-1338. [Medline] [CrossRef]

26) Cho YR, Hong BY, Lim SH, et al.: Effects of joint effusion on proprioception in patients with knee osteoarthritis: a single-blind, randomized controlled clinical trial. Osteoarthritis Cartilage, 2011, 19: 22-28. [Medline] [CrossRef]

27) Garsden LR, Bullock-Saxton JE: Joint reposition sense in subjects with unilateral osteoarthritis of the knee. Clin Rehabil, 1999, 13: 148-155. [Medline] [CrossRef]

28) Lord SR, Menz HB, Tiedemann A: A physiological profile approach to falls risk assessment and prevention. Phys Ther, 2003, 83: 237-252. [Medline]

29) Cress ME, Buchner DM, Questad KA, et al.: Exercise: effects on physical functional performance in independent older adults. J Gerontol A Biol Sci Med Sci, 1999, 54: M242-M248. [Medline] [CrossRef]

30) Taylor AH, Cable NT, Faulkner G, et al.: Physical activity and older adults: a review of health benefits and the effectiveness of interventions. J Sports Sci, 2004, 22: 703-725. [Medline] [CrossRef]

31) Yan T, Wilber KH, Aguirre R, et al.: Do sedentary older adults benefit from community-based exercise? Results from the Active Start program. Gerontologist, 2009, 49: 847-855. [Medline] [CrossRef]

32) Lee YS: Gender differences in physical activity and walking among older adults. J Women Aging, 2005, 17: 55-70. [Medline] [CrossRef]

33) McAuley E: Self-efficacy and the maintenance of exercise participation in older adults. J Behav Med, 1993, 16: 103-113. [Medline] [CrossRef] 
34) van Stralen MM, Lechner L, Mudde AN, et al.: Determinants of awareness, initiation and maintenance of physical activity among the over-fifties: a Delphi study. Health Educ Res, 2010, 25: 233-247. [Medline] [CrossRef]

35) Beneka A, Malliou P, Fatouros I, et al.: Resistance training effects on muscular strength of elderly are related to intensity and gender. J Sci Med Sport, 2005, 8: 274-283. [Medline] [CrossRef]

36) Toraman F, Sahin G: Age responses to multicomponent training programme in older adults. Disabil Rehabil, 2004, 26: 448-454. [Medline] [CrossRef]

37) Littbrand H, Carlsson M, Lundin-Olsson L, et al.: Effect of a high-intensity functional exercise program on functional balance: preplanned subgroup analyses of a randomized controlled trial in residential care facilities. J Am Geriatr Soc, 2011, 59: 1274-1282. [Medline] [CrossRef]

38) Nakagava $\mathrm{K}$, Inomata $\mathrm{N}$, Konno $\mathrm{Y}$, et al.: The characteristics of a simple exercise program under the instruction of physiotherapists-for genereal elderly people and frail elderly people. J Phys Ther Sci, 2008, 20: 197-203. [CrossRef]

39) Kim WJ, Chang M, An DH: Effects of a community-based fall prevention exercise program on activity participation. J Phys Ther Sci, 2014, 26 651-653. [Medline] [CrossRef] 